\title{
Evaluation of the Seasonality and Extraction Method on the Polar Extracts of Croton grewioides Baill. by Chromatogram Fingerprinting and Isolation of a New Triglycosylated Flavonoid
}

\author{
Vilma M. J. Prado, ${ }^{a}$ Raphael A. de Jesus, ${ }^{a}$ Julio M. A. Oliveira, ${ }^{a}$ Camila S. A. Pereira, ${ }^{b}$ \\ Arie F. Blank, ${ }^{c}$ Edenir R. Pereira-Filho, ${ }^{\circledR d}$ Quezia B. Cass, ${ }^{\circ d}$ Juliana M. de Lima, ${ }^{d}$ \\ Antonio G. Ferreira, ${ }^{d}$ Paulo C. L. Nogueira ${ }^{a}$ and Valéria R. S. Moraes ${ }^{\circledR} * a$ \\ ${ }^{a}$ Departamento de Química, Universidade Federal de Sergipe, \\ Av. Marechal Rondon s/n, 49100-000 São Cristovão-SE, Brazil \\ ${ }^{b}$ Núcleo de Graduação em Engenharia Agronômica, Universidade Federal de Sergipe, \\ Campus do Sertão, Rodovia Engenheiro Jorge Neto, km 3, Silos, \\ 49680-000 Nossa Senhora da Glória-SE, Brazil \\ 'Departamento de Engenharia Agronômica, Universidade Federal de Sergipe, \\ Av. Marechal Rondon s/n, 49100-000 São Cristovão-SE, Brazil \\ ${ }^{d}$ Departamento de Química, Universidade Federal de São Carlos, \\ Rodovia Washington Luiz, km 235, 13565-905 São Carlos-SP, Brazil
}

\begin{abstract}
Croton grewioides Baill. popularly known as "canelinha" or "canelinha-de-cheiro" has been used for the treatment of influenza, antitussive, febrifuge and headache; however, the study of its phytochemical composition is limited. The aim of this study was to investigate the effect of the extraction method and seasonality through leaf extracts of four accessions of Croton grewioides by fingerprint chromatograms aided by principal component analysis to analyze the differences and similarities among the samples. We aimed also to provide chemical characterization of isolated secondary metabolites using semi-preparative liquid chromatography. The results showed that only the chemical profile of the methanolic extracts of accessions 101 and 113 were influenced by the seasonality. For the first time, four flavonoids were isolated through semi-preparative chromatography in this species, characterized as quercetin 3-O- $\beta$-D-galactopyranosyl- $(1 \rightarrow 2)$ - $\alpha$-L-rhamnopyranoside- $(1 \rightarrow 6)-\alpha$-L-rhamnopyranoside $(\mathbf{1})$, quercetin 3-O- $\beta$-D-galactopyranosyl- $(1 \rightarrow 2)$ - $\alpha$-apiopyranoside- $(1 \rightarrow 6)-\alpha$-L-rhamnopyranoside $(\mathbf{2})$, quercetin 3-O-glucopyranoside (3) and 3-O-methyl-quercetin (4), the flavonoid (2) has been recognized as a new triglycosylated derivative.
\end{abstract}

Keywords: chemometric analysis, Croton grewioides Baill., fingerprint chromatograms, flavonoids glycosides

\section{Introduction}

The genus Croton L. is the most studied of family Euphorbiaceae, which belongs to the Crotonoideae subfamily consisting of about 1300 species, and it is of great importance in the Brazilian flora, with about 300 species. Croton grewioides Baill. is found in all states of the Brazilian Northeast region, occurring exclusively in the semi-arid region, regularly in sandy soils. Popularly it is

*e-mail: valrsmoraes@uol.com.br known as "canelinha", "caatinga de cheiro" or "canelinhade-cheiro" due the aroma exhaled from its leaves. An ethnobotanical survey in northeast of Brazil showed that tea made from the leaves and branches of this species have been used for the treatment of influenza, antitussive, febrifuge and headache..$^{1-5}$

To the best of our knowledge, few phytochemical studies reporting biological activities of essential oils and extracts from this species have been published in the literature. ${ }^{3,6-10}$ Only one report, a PhD thesis, ${ }^{11}$ was found during the bibliographic search which describes 
the phytochemical study of this species showing the isolation of nine diterpenes, three phenolic, and one steroid. Previous phytochemical studies ${ }^{6}$ on Croton species showed the presence of monoterpenoids, diterpenoids, sesquiterpenoids, triterpenoids, steroids, alkaloids and phenolic derivatives, mainly flavonoids, lignans and proanthocyanidins.

Considering the fact that the chemical composition of the plant is affected by, among other factors, the change of season, place of origin and genetic variability of the accessions which may affect its pharmacological activities, this work investigated the effect of these factors, as well as the method of extraction of the leaf extracts, on their fingerprint chromatograms, by high performance liquid chromatography-diode array detector (HPLC-DAD), of four accessions from $C$. grewioides. ${ }^{12-15}$ A fingerprint chromatogram is considered a chromatographic pattern where it is possible to observe similarities or differences among plant samples, describing their chemical complexities and assisting in their characterizations, especially in research related to the medicinal use of plants..$^{16,17}$ To verify which of these factors is more important in discriminating samples, chemometric analysis was carried out with the obtained fingerprint chromatograms.

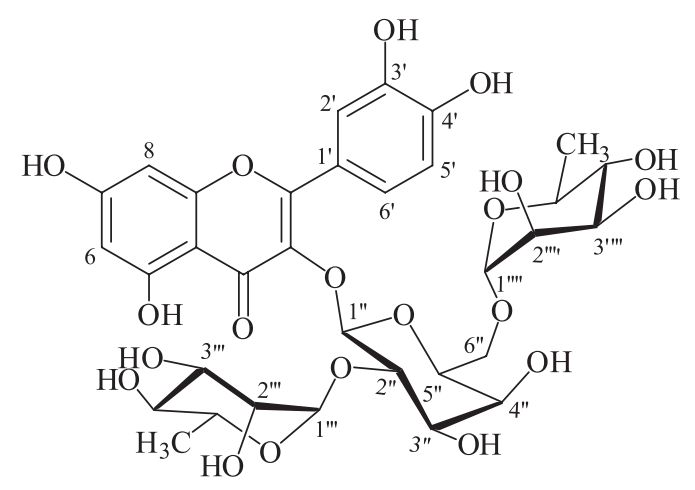

1<smiles>O=c1c(O[C]2O[C@@H](O)[C@@H](O)[C@H](O)[C@H]2O)c(-c2ccc(O)c(O)c2)oc2cc(O)cc(O)c12</smiles>

3
Moreover, semi-preparative chromatography was used to isolate quercetin 3-O- $\beta$-D-galactopyranosyl$(1 \rightarrow 2)$ - $\alpha$-L-rhamnopyranoside- $(1 \rightarrow 6)$ - $\alpha$-L-rhamnopyranoside (1), quercetin 3-O- $\beta$-D-galactopyranosyl$(1 \rightarrow 2)$ - $\alpha$-apiopyranoside- $(1 \rightarrow 6)$ - $\alpha$-L-rhamnopyranoside (2), a new flavonoid triglycosides, quercetin 3-O-glucopyranoside (3) and 3-O-methyl-quercetin (4) (Figure 1). The four flavonoid derivatives were herein for the first time obtained from C. grewioides. Their chemical structural identification was carried out by spectroscopic methods, including 1D and 2D nuclear magnetic resonance (NMR) spectroscopy and high-resolution mass spectrometry (HRMS).

\section{Experimental}

Instrumentation

The fingerprint chromatograms were obtained using a Shimadzu liquid chromatograph (Kyoto, Japan) Prominence model, equipped with two high pressure pumps LC-20AT, a column oven CTO-20A, a vacuum degasser DGU-20A3 model, SIL-20AHT autosampler, and an SPD-M20A diode array detector (DAD) system

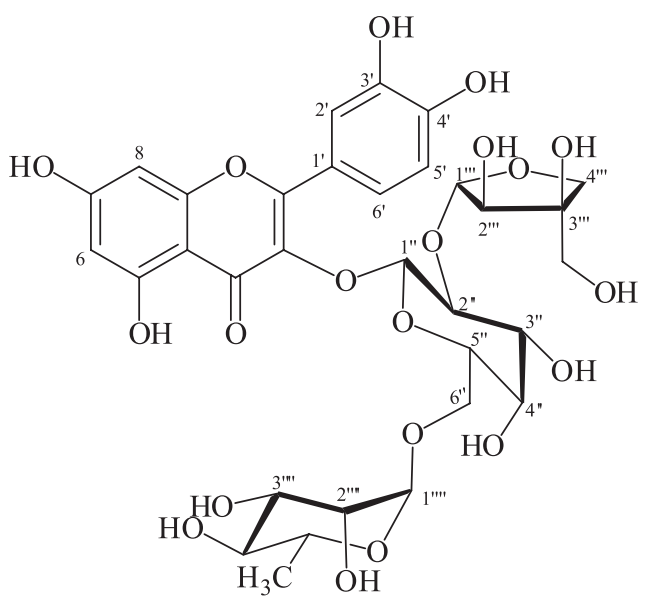

\section{2}<smiles>COc1c(-c2ccc(O)c(O)c2)oc2cc(O)cc(O)c2c1=O</smiles>

Figure 1. Chemical constituents from C. grewioides. 
coupled with a CBM-20A interface. Data collection was performed using LC Solution software. An analytical Kinetex $\mathrm{C}_{18}$ column $(250 \times 4.6 \mathrm{~mm}$ internal diameter (i.d.); $5 \mu \mathrm{m}$ particle diameter, Phenomenex, Torrance, CA, USA) was used.

The isolation of the flavonoids was carried out using a semi-preparative HPLC-UV, Shimadzu (Kyoto, Japan), Prominence model, equipped with two high pressure pumps LC-6AD, a vacuum degasser DGU-20A3R, FRC-10A fraction collector, SIL-20A autosampler, SPD-20A UV-Vis spectrophotometer detector system coupled with a CBM-20A interface and a column oven CTO-20A model. A semi-preparative hexyl-phenyl Luna ${ }^{\circledR}$ column $(250 \times 10 \mathrm{~mm}$ i.d.; $10 \mu \mathrm{m}$ particle diameter, Phenomenex, Torrance, CA, USA) was used.

The 1D $\left({ }^{1} \mathrm{H}\right.$ and $\left.{ }^{13} \mathrm{C}\right)$ and 2D NMR (homonuclear correlation (COSY), heteronuclear single quantum coherence (HSQC), heteronuclear multiple bond coherence (HMBC)) spectra of the isolated compounds were acquired at $299 \mathrm{~K}$ with the use of a Bruker Avance III instrument (14.1 Tesla, Ultrashield Plus ${ }^{\circledR}$, Karlshure, Germany) fitted with an automatic sample changer and a triple resonance cryoprobe inverse of $5 \mathrm{~mm}\left({ }^{1} \mathrm{H} /{ }^{13} \mathrm{C} /{ }^{15} \mathrm{~N}\right)$ with $\mathrm{z}$-field gradient. Data collection and processing were carried out using the Bruker software Topspin 3.2 version. The spectra were referenced to tetramethylsilane (TMS) at $0.0 \mathrm{ppm}$ and the chemical shifts of all hydrogens and carbons were reported using $\delta$ values.

The ultra-high performance liquid chromatography (UHPLC-HRMS) analysis was carried out on an Agilent 1290 Infinity II LC system (Agilent Technologies, CA, USA) coupled with a high-resolution mass spectrometer containing a quadrupole time-of-flight Impact HD QTOFTM mass spectrometer (Bruker Daltonics, Bremen, Germany) equipped with an electrospray ion source (ESI). The optimized chromatography conditions were detailed as follows: Hypersil GOLD C8 Javelin ${ }^{\mathrm{TM}}$ guard column $(10 \times 2.1 \mathrm{~mm}, 5 \mu \mathrm{m}$ particle diameter, Thermo Scientific, Waltham, MA, USA), with the temperature set at $40{ }^{\circ} \mathrm{C}$, mobile phase $\mathrm{A}(0.1 \%$ formic acid in water $)$ and $\mathrm{B}$ (acetonitrile) were used at a flow-rate of $0.2 \mathrm{~mL} \mathrm{~min}^{-1}$, with gradient elution of $0-5 \mathrm{~min}, 10-100 \% \mathrm{~B}$. The injection volume was $5 \mu \mathrm{L}$. The Impact HDQTOFTM mass spectrometer parameters were set as follows: negative ion mode, capillary voltage, $2500 \mathrm{~V}$; end plate offset, $-500 \mathrm{~V}$; nebulizer, 4.0 bar; dry heater temperature, $180{ }^{\circ} \mathrm{C}$; dry gas flow, $9 \mathrm{~L} \mathrm{~min}^{-1}$, collision cell energy, $5 \mathrm{eV}$; transfer time, $70 \mu$ s, pre pulse time, $5 \mu$ s, and full-MS scan range, $\mathrm{m} / \mathrm{z}$ 100-1000. In addition, external mass spectrometer calibration was carried out with sodium formate cluster $\left(1 \mathrm{mmol} \mathrm{L}^{-1}\right.$ sodium formate in water/acetonitrile, 1/1 (v/v)) in quadratic high-precision calibration (HPC) regression mode. The calibration solution was injected at the end of the analytical run and all the spectra were calibrated. The data analysis was processed by using Bruker Compass DataAnalysis 4.2 software (Bruker Daltonics, Bremen, Germany), and Bruker Smart Formula provided a list of possible elemental formulas. The confirmation of elemental compositions was established with less than $10 \mathrm{ppm}$ mass accuracy.

\section{Reagents and plant materials}

For sample preparation and HPLC analyses, HPLC-grade solvents such as acetonitrile (Tedia, Fairfield, OH, USA), methanol (JT Backer, Philipsburg, PA, USA) and ethanol (PanReac, Barcelona, Spain) and analytical grade formic acid 88\% (v/v) (JT Baker, Philipsburg, PA, USA) were used. Deionized water was purified by a Milli- ${ }^{\circledR}$ system (Millipore, São Paulo, SP, Brazil).

The leaves of the four accessions of Croton grewioides Baill. were collected at the Germplasm Active Bank of the Federal University of Sergipe, located at the Experimental Farm “Campus Rural da UFS" in São Cristóvão, Sergipe state, Brazil, in June 2016 (winter) and January 2017 (summer). Voucher specimens were identified and deposited at the herbarium of the Federal University of Sergipe, Department of Biology, under numbers 28256, 25138, 28251, 23259, referring to accessions 101, 107, 113 and 126, respectively. All the accessions originated from Sergipe state; accession 101 (1055'17.8" S; 3706'04.1" W) from Poço Verde municipality while $107\left(09^{\circ} 58^{\prime} 06.5^{\prime \prime}\right.$ S; 37 $51^{\circ} 48.4$ " W), 113 (0958'06.9" S; 3751'49.1' W) and 126 (0957'55.6" S; $37^{\circ} 51^{\prime} 49.8^{\prime \prime}$ W) from Poço Redondo municipality. The material was dried in a forced air circulation oven at $50{ }^{\circ} \mathrm{C}$ for 3 days.

\section{Preparation of the crude extracts}

Hydroalcoholic extracts (HW-hydroalcoholic winter and HS-hydroalcoholic summer) were obtained from $2 \mathrm{~g}$ of leaf by maceration using $100 \mathrm{~mL} \mathrm{50 \%} \mathrm{v/v} \mathrm{ethanol} \mathrm{(HPLC}$ grade) for $24 \mathrm{~h}$ at ambient temperature. Thereafter, a simple filtration was performed, leaving the extract in rest until complete evaporation of the solvents under a gentle stream of air. The methanolic extracts (MW-methanolic winter and MS-methanolic summer) were prepared by maceration. To that, $2 \mathrm{~g}$ of leaves were placed in Erlenmeyer flask with $100 \mathrm{~mL}$ of methanol (HPLC grade) and left at rest for $24 \mathrm{~h}$. Then, the solutions were filtered, and the solvent removed by using a rotary evaporator at $50{ }^{\circ} \mathrm{C}$. The aqueous extract (DW-decoction winter; DS-decoction summer) 
was obtained by the decoction method by adding $2 \mathrm{~g}$ of leaves in a beaker containing $200 \mathrm{~mL}$ of boiling ultrapure water under a heating plate and leaving it to boil for $90 \mathrm{~s}$. After this time, the beaker was removed from the heating plate and allowed to stand for $10 \mathrm{~min}$ and then filtered. The remaining solution was frozen lyophilized under the following conditions: temperature of $-54{ }^{\circ} \mathrm{C}$ and pressure below $90 \mu \mathrm{Hg}$. In total, 24 extracts were obtained from the two collections (winter and summer).

\section{Solid phase extraction procedures}

Solid-phase extraction $\left(\mathrm{C}_{18}\right.$ cartridge, JT Baker, $100 \mathrm{mg}, 40 \mu \mathrm{m}$ APD, $60 \AA$ ) was carried out to all samples prior to the HPLC analyses. Thus, an aliquot of $10 \mathrm{mg}$ of hydroalcoholic, aqueous and methanolic extracts were dissolved, separately, in $1 \mathrm{~mL}$ of $60 \% \mathrm{v} / \mathrm{v}$ methanol in water, in $40 \% \mathrm{v} / \mathrm{v}$ methanol in water and $100 \%$ methanol, respectively. All solutions were vortex mixed for a few seconds before centrifuging them at 11,866 $\mathrm{g}$ force for $5 \mathrm{~min}$. Initially, the cartridge was conditioned with $1 \mathrm{~mL}$ of methanol, followed by $1 \mathrm{~mL}$ of water. Subsequently, a volume of $50 \mu \mathrm{L}$ of the centrifuged solutions $\left(10 \mathrm{mg} \mathrm{mL}^{-1}\right)$ was eluted with $1 \mathrm{~mL}$ of a mixture $50 \% \mathrm{v} / \mathrm{v}$ methanol in water followed by $1 \mathrm{~mL}$ of methanol.

\section{HPLC analysis}

An aliquot of $25 \mu \mathrm{L}$ of the clean-up extracts was injected at HPLC-DAD system. This procedure was carried out in quadruplicate for each sample. Chromatographic analyses were performed on the analytical $\mathrm{C}_{18}$ column following the conditions: mobile phase consisting of $0.5 \%$ aqueous formic acid (v/v, A) and acetonitrile (B). The gradient elution was: $5-15 \%$ (B) in $8 \mathrm{~min}, 15-19 \%$ (B) in $15 \mathrm{~min}$, $19-24 \%$ (B) in $10 \mathrm{~min}, 24 \%$ isocratic (B) for $10 \mathrm{~min}$, $24-100 \%$ (B) in $15 \mathrm{~min}, 100 \%$ isocratic (B) for $10 \mathrm{~min}$. The system was then restored to initial conditions in $15 \mathrm{~min}$, and each run was followed by equilibration time of $40 \mathrm{~min}$ before the next injection. The solvent flow rate was

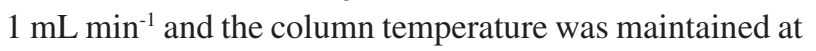
$25^{\circ} \mathrm{C}$. The DAD was set at $320 \mathrm{~nm}$.

\section{Chemometric analysis}

Multivariate data analysis was performed out using Pirouette software. ${ }^{18}$ Pretreatment (peak alignment by the correlation optimized warping technique) and preprocessing (mean centered) of the data matrixes were applied ${ }^{19}$ following the methodology described by Gomes et al. ${ }^{20}$
Isolation by semi-preparative HPLC-UV

For the chromatographic separations, solutions containing $60 \mathrm{mg} \mathrm{mL}^{-1}$ of the decoction extract from 107 accession (summer, 107DS) were prepared in methanol and ultrapure water $(4: 6 \mathrm{v} / \mathrm{v})$; subsequently, it was centrifugated prior to the HPLC analyses. The binary gradient elution system consisted of an aqueous solution of formic acid $0.5 \%(\mathrm{v} / \mathrm{v})(\mathrm{A})$ and acetonitrile (B), and separation was achieved using the following gradient: $5-28 \%$ (B) in $15 \mathrm{~min}, 28-37 \%$ (B) in $10 \mathrm{~min}, 37-60 \%$ (B) in $15 \mathrm{~min}, 60-100 \%$ (B) in $5 \mathrm{~min}$ and maintained at $100 \%$ for $10 \mathrm{~min}$ (clean-up) before returning to the initial conditions in $15 \mathrm{~min}$ and then conditioning for a further $25 \mathrm{~min}$, with $300 \mu \mathrm{L}$ injection volume and solvent flow rate $4 \mathrm{~mL} \mathrm{~min}^{-1}$. The elution was monitored based on UV absorption at $320 \mathrm{~nm}$, the column temperature was maintained at $25^{\circ} \mathrm{C}$ and thirty-five chromatographic runs were performed.

\section{Results and Discussion}

All accessions of Croton grewioides Baill. used in this work belong to the Active Germplasm Bank (AGB) of the Federal University of Sergipe, where one of the objectives is the creation and maintenance of genetic diversity. ${ }^{21}$ Considering that in the northeastern region of Brazil the four seasons of the year are not well defined, it was decided to investigate only samples collected during the winter and summer season, since they present a more significant temperature variation (during the winter the temperature ranges from 18 to $26{ }^{\circ} \mathrm{C}$ and in the summer from 21 to $32{ }^{\circ} \mathrm{C}$ ) and rainfall index [June 2016 (winter)-total: $265 \mathrm{~mm}$, mean value: $8.8 \mathrm{~mm}$; January 2017 (summer)total: $18.26 \mathrm{~mm}$, mean value: $0.59 \mathrm{~mm}] .{ }^{22}$

\section{Chromatographic conditions and optimization procedures}

In order to achieve the best chromatographic profiles, different chromatographic conditions were investigated, such as organic modifier, stationary phases $\left(\mathrm{C}_{18}\right.$ and hexylphenyl), and column temperatures.

The highest number of characteristic bands detectable was achieved at $320 \mathrm{~nm}$ with gradient elution using acetonitrile as organic modifier. The use of $0.5 \% \mathrm{v} / \mathrm{v}$ formic acid aqueous solution as the solvent $B$ was important for the chromatographic peak shape, since the use of a slightly acidic solution in the mobile phase restricts the ionization of some compounds commonly found in Croton species. ${ }^{23-27}$ The $\mathrm{C}_{18}$ stationary phase, maintained at a temperature of $25^{\circ} \mathrm{C}$ and the DAD selected at a wavelength of $320 \mathrm{~nm}$ allowed the observation of a greater number of bands with good 
resolution. Figure 2 illustrates the chromatograms obtained for the evaluated samples considering the extraction methods, the accessions and the season of collection.

The chromatograms represented in Figure 2 distinguish the methanolic extracts from the others in that it shows eluting peak after $40 \mathrm{~min}$. It is worth noticing that the peaks at 55.7; 56.0 and $56.3 \mathrm{~min}$ are present only in accession 101. Principal component analysis (PCA) was used to better explain these results.
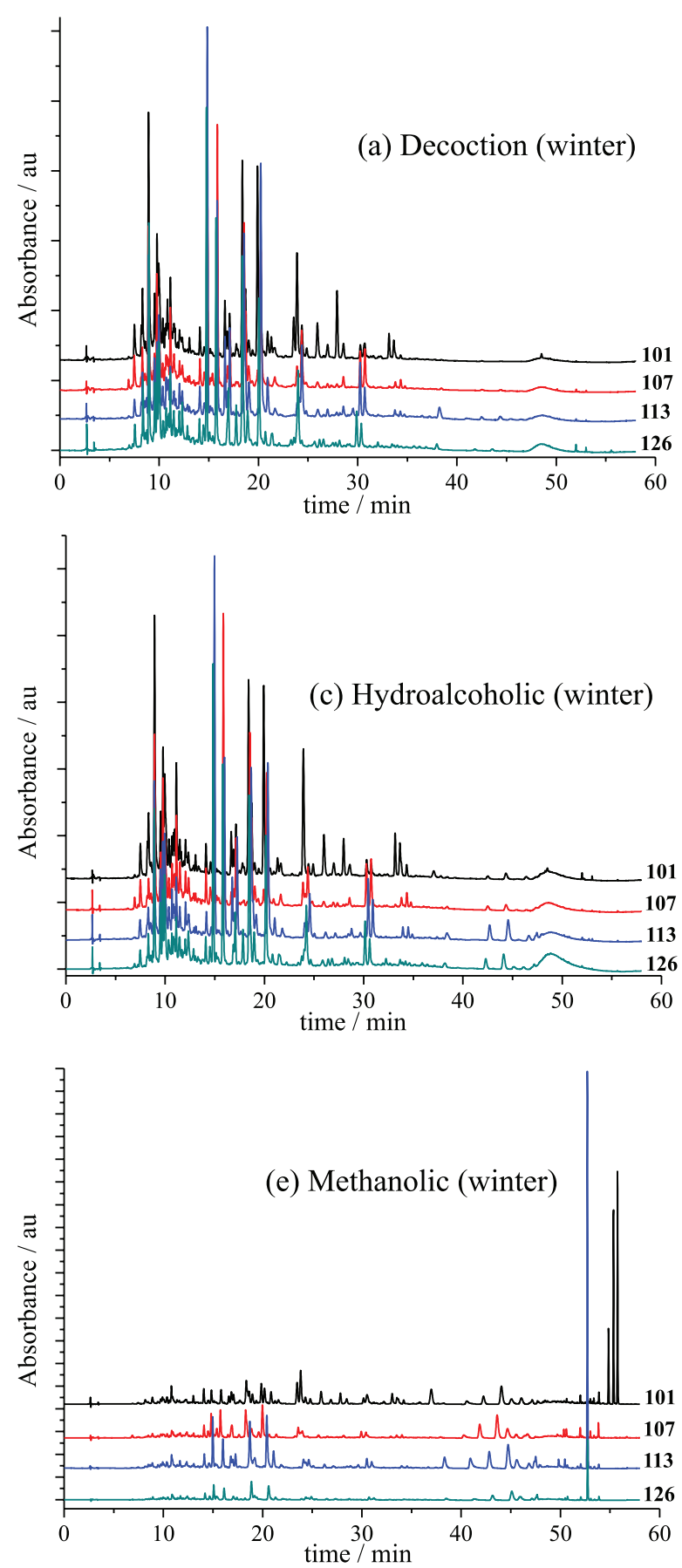

\section{Principal component analysis (PCA)}

PCA is a multivariate statistical analysis that aims to reduce the dimensionality of the original data set showing the correlation among several variables in terms of a smaller number of underlying factors called principal components (PCs) without losing much information. This method allows the exploration of data through the combined analysis of the scores and loadings graphs of samples, without prior
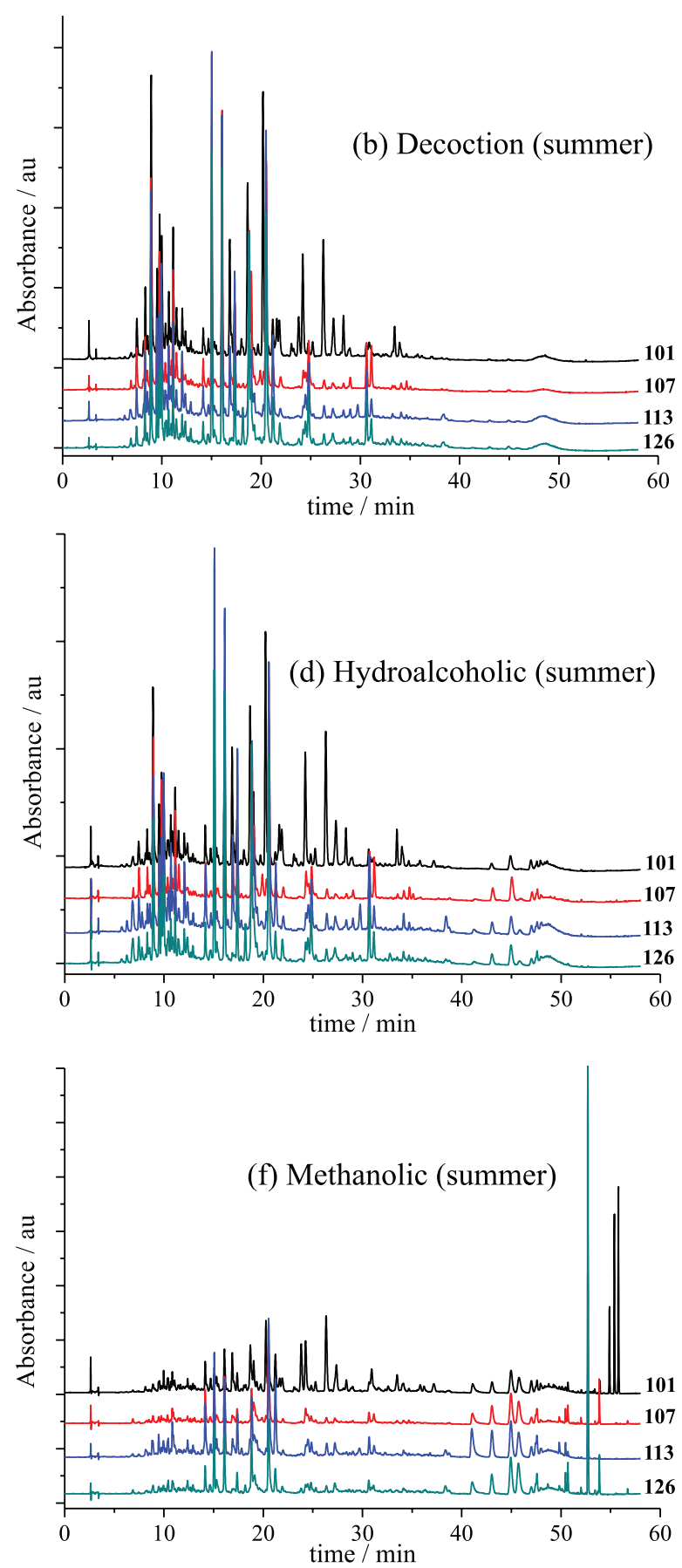

Figure 2. HPLC-DAD fingerprint chromatograms at $320 \mathrm{~nm}$ of the extracts from four accessions of $C$. grewioides, prepared by different methods and collected at different seasons. 
knowledge of their classification or to which specific group they belong. ${ }^{28,29}$

After pretreatment and preprocessing steps, the chromatographic data were organized into a matrix containing 96 lines (samples) and 543 columns (variables: retention time, $58 \mathrm{~min}$ ) being submitted to the principal component analysis, obtaining the scores chart PC1 versus $\mathrm{PC} 2$ (Figure 3). The first two principal components (PC1 and $\mathrm{PC} 2$ ) describe $38.7 \%$ of the total data variance $(\mathrm{PC} 1=24.0 \%$ and $\mathrm{PC} 2=14.7 \%)$, being used to classify and discriminate the samples.

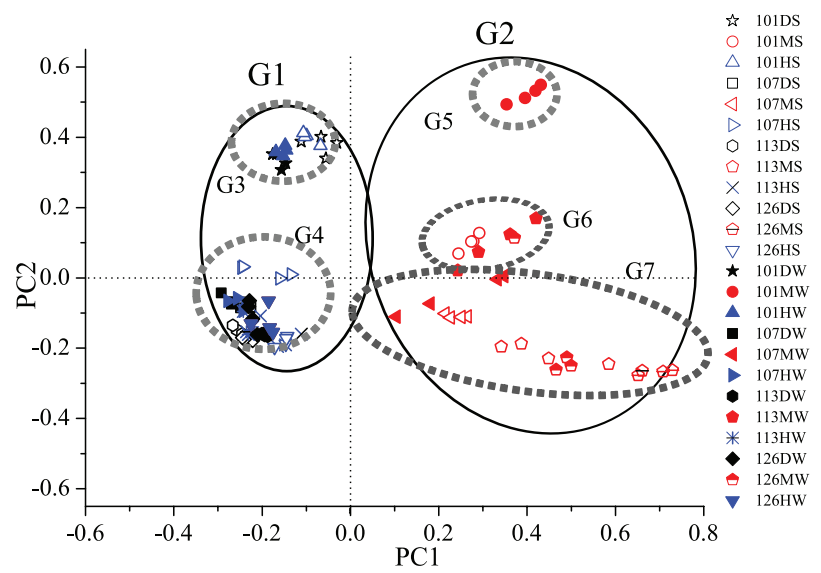

Figure 3. Scores plot (PC1 versus $\mathrm{PC} 2$ ) of the samples from C. grewioides (101, 107, 113 and 126: leaf samples of C. grewioides accessions; HW: hydroalcoholic winter, HS: hydroalcoholic summer, MW: methanolic winter, MS: methanolic summer, DW: decoction winter and DS: decoction summer; methanolic extracts are shown in red, hydroalcoholic extracts in blue and decoction extracts in black).

On the basis of the first two principal components (PCs), the following was observed: the formation of two large distinct groups (G1 and G2), considering only the extraction method, being one group formed by the methanolic samples in $\mathrm{PC} 1$ positive $(\mathrm{G} 2)$ and the other by the decoction and hydroalcoholic samples in PC1 negative (G1) indicating that the chemical profiles of methanolic extracts are significantly different to the other two. This data corroborates the differences observed in the chromatograms depicted at Figure 2.

Within these two groups, the formation of five other groups (G3 to G7) was observed. Samples 101HS, 101HW, 101DS, and 101DW formed the G3 group, presenting PC1 negative and PC2 positive, while all decoction and hydroalcoholic samples from other accessions formed the G4 group, which is characterized by negative PC1 and PC2 values, except for the 107HS sample that tends to values closed to zero in PC2.

The G5 group is formed only by the 101MW samples, while the G6 group by the 101MS and 113MW samples with PC1 and PC2 positive values. Samples 107MW,
107MS, 113MS, 126MS and 126MW form the G7 group with positive values in PC1 and negative in PC2. It is interesting to observe the significant separation of all the samples of accession 101 in relation to the samples of the other accessions, except the 101MS that resembles 113MW (G6), which may be related to the geographical origin of this accession, since it is the only one that comes from the municipality of Poço Verde, suggesting that it may be a genetic variety or an one with better environmental adaptability. However, it is important to emphasize that studies with a greater number of accessions, mainly for the municipality of Poço Verde, are necessary to verify whether the genetic variation observed among the accessions is related to their geographical origin.

Through a visual analysis of Figure 4, it is possible to perceive similarities and differences between the chromatograms of the methanolic extracts from accessions 101 and 113, suggesting that the seasonality effect can be observed through the compounds present in these extracts. However, only through the graph in Figure 3 this effect becomes clearly evident, because they are not clustered in the scores graph (Supplementary Information (SI) section, Figure S1). On the other hand, there was no significant variation of the compounds present in the hydroalcoholic and decoction extracts between the two seasons. These chromatograms are provided as SI (Figures S2 and S3).

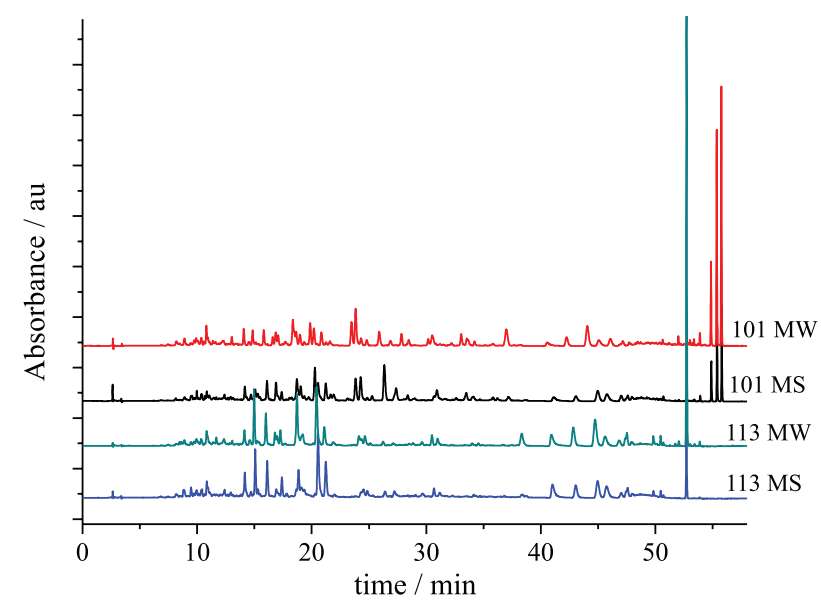

Figure 4. Comparison of HPLC-DAD fingerprint chromatograms of the methanolic extracts from 101 and 113 accessions of $C$. grewioides (MW: methanolic winter, MS: methanolic summer).

Regarding the differences among accessions, it can be assumed that accessions 107 and 126 must be genetically very close, because all their extracts tended to cluster, the hydroalcoholic and decoction in G4, and the methanolic in G7. The results obtained in this work for these accessions have been confirmed through studies of their essential oils and genetic variability (unpublished data). 
In order to identify which variables contribute to the observed differentiation among the samples, the loadings graph (Figure 5) were analyzed..$^{30-32}$

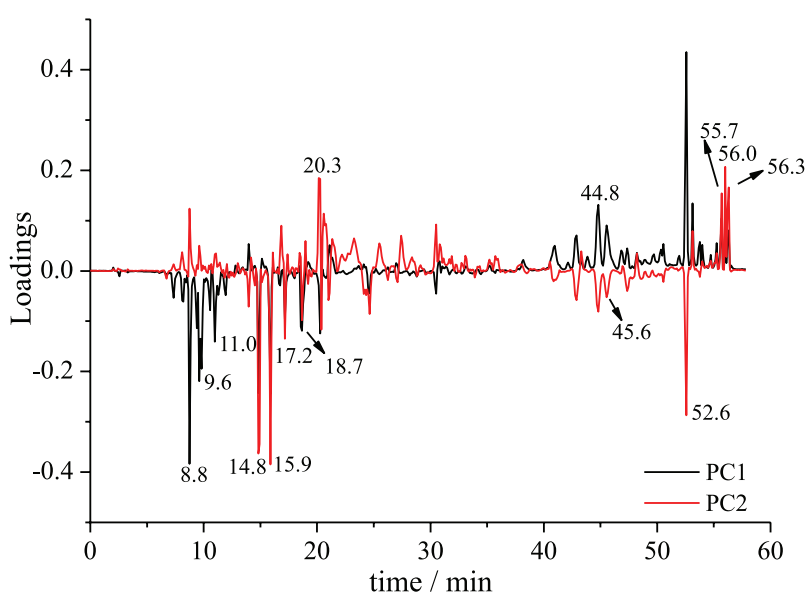

Figure 5. Loadings plot of $C$. grewioides samples.

Thus, the chromatographic bands with retention times $44.8 ; 45.6 ; 52.6 ; 55.7 ; 56.0$ and 56.3 min characterized the methanolic extract samples, while those with retention times $8.8 ; 9.6 ; 11.0 ; 14.8 ; 15.9 ; 17.2 ; 18.7$ and $20.3 \mathrm{~min}$ characterized the hydroalcoholic and decoction samples. The differences observed in the chromatograms were clearly shown in the chemometric data (Figure 3). The projection of samples from accession 101 (hydroalcoholic, decoction and methanolic-summer and winter), suggest that this is a specific accession because it separates itself from others samples originated from the same extraction and season of collection, presenting characteristic bands with retention time 8.8 ; 9.6; 11.0 and $20.3 \mathrm{~min}$ for 101HS, 101HW, 101DS, and 101DW; and 55.7, 56.0 and 56.3 min for 101MS and 101MW.

\section{Semi-preparative isolation}

The Figure 6 illustrates the semi-preparative chromatogram used to isolate the flavonoids yielding, after thirty-five chromatographic runs, $5.6 \mathrm{mg}$ compound $\mathbf{1}$ $\left(\mathrm{t}_{\mathrm{R}}-\mathrm{LC}: 17.60 \mathrm{~min}, \mathrm{UV} \lambda_{\text {max }}: 255,354 \mathrm{~nm}\right), 9.9 \mathrm{mg}$ compound $2\left(\mathrm{t}_{\mathrm{R}}-\mathrm{LC}\right.$ : $18.06 \mathrm{~min}$, UV $\left.\lambda_{\max } 255,353 \mathrm{~nm}\right)$, $8.8 \mathrm{mg}$ compound $3\left(\mathrm{t}_{\mathrm{R}}-\mathrm{LC}\right.$ : $20.91 \mathrm{~min}$, UV $\lambda_{\max }: 255$, $354 \mathrm{~nm})$; and $1.0 \mathrm{mg}$ compound $4\left(\mathrm{t}_{\mathrm{R}}-\mathrm{LC}: 31.84 \mathrm{~min}\right.$, UV $\left.\lambda_{\max }: 255,356 \mathrm{~nm}\right)$, which were directly used for UHPLC-HRMS and NMR experiments. The UV spectra of each compound were obtained with the aid of the diode array detector and the data compared with literature..$^{33,34}$

\section{Structural identification of flavonoids}

The structure identification of four flavonoids was

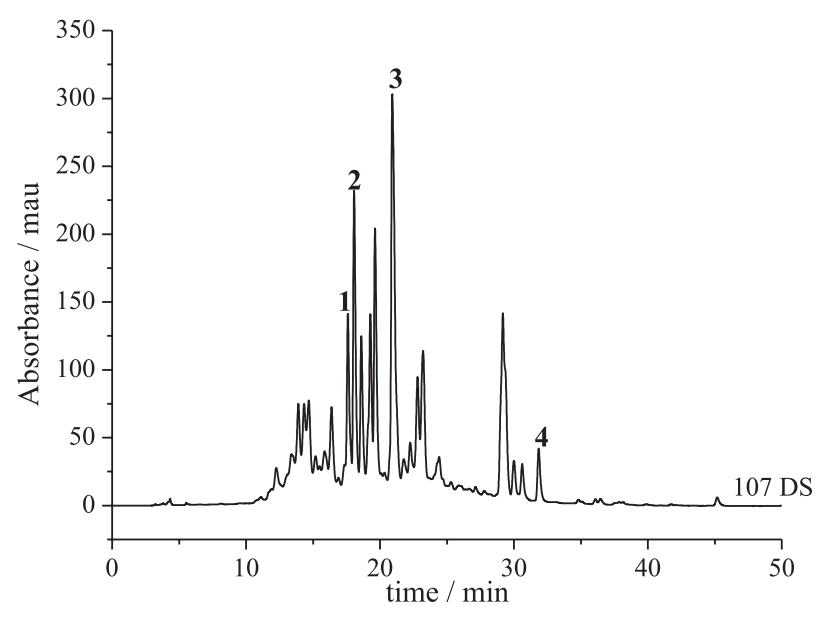

Figure 6. Semi-preparative HPLC-UV chromatogram from 107DS extract (detection wavelength, $320 \mathrm{~nm}$; concentration: $60 \mathrm{mg} \mathrm{mL}^{-1}$ ).

based on 1D and 2D NMR spectroscopy. The molecular formula for compound $\mathbf{1}$ was established as $\mathrm{C}_{33} \mathrm{H}_{40} \mathrm{O}_{20}$ based on HRMS data $[\mathrm{M}-\mathrm{H}]^{-}$at 755.2010. In the ${ }^{1} \mathrm{H}$ NMR $\left(600 \mathrm{MHz}, \mathrm{MeOH}-d_{4}\right)$ spectrum, five aromatic protons at $\delta_{\mathrm{H}} 6.17(\mathrm{~d}, 1 \mathrm{H}, J 2.1 \mathrm{~Hz}, \mathrm{H}-6), 6.37$ (d, 1H, J $\left.2.1 \mathrm{~Hz}, \mathrm{H}-8\right)$, 7.68 (d, 1H, J 2.2 Hz, H-2'), 6.87 (d, 1H, J 8.5 Hz, H-5') and $7.56(\mathrm{dd}, 1 \mathrm{H}, J 8.5,2.2 \mathrm{~Hz}, \mathrm{H}-6$ ') defined a quercetin aglycon. Three doublets at $\delta_{\mathrm{H}} 5.65(1 \mathrm{H}, J 7.8 \mathrm{~Hz}), 5.20$ $(1 \mathrm{H}, J 1.5 \mathrm{~Hz})$ and $4.54(1 \mathrm{H}, J 1.6 \mathrm{~Hz})$ indicated the presence of three anomeric protons, which correlated to carbons at $\delta_{\mathrm{C}} 101.0$ (C-1"'Gal), 102.6 (C-1"" $\left.{ }^{\text {Rha }}\right)$ and 101.9 (C-1"'"Rha), respectively, in the HSQC spectra. In addition, the presence of two doublets for two methyl group at $\delta_{\mathrm{H}} 1.17\left(3 \mathrm{H}, J 6.2 \mathrm{~Hz} ; \delta_{\mathrm{C}} 17.9\right)$ and $0.95(3 \mathrm{H}, J 6.3 \mathrm{~Hz}$; $\left.\delta_{\mathrm{C}} 17.4\right)$ confirmed the presence of a $\beta$-galactose unit and two $\alpha$-rhamnose units. The sequence of the trisaccharide residue was determined from $\mathrm{HMBC}$ spectra which displayed important correlations between hydrogens and carbons, mainly of H-1"' $\left(\delta_{\mathrm{H}} 5.20\right)$ and C-2" $\left(\delta_{\mathrm{C}} 77.5\right)$ denoting a $1 \rightarrow 2$ linkage between one of the rhamnose units and the galactose unit. Correlations between C- 6 ", $\left(\delta_{\mathrm{C}} 67.0\right)$ of the galactose and the anomeric proton $\mathrm{H}-1$ '”, $\left(\delta_{\mathrm{H}} 4.54\right)$ of the another rhamnose residue indicated a $1 \rightarrow 6$ linkage between them. In addition, the correlation between anomeric proton $\mathrm{H}-1$ " $\left(\delta_{\mathrm{H}} 5.65\right)$ of the galactose and C-3 $\left(\delta_{\mathrm{C}} 134.6\right)$ of the quercetin identified the linkage between galactose moiety and the aglycone at C-3. Therefore, compound $\mathbf{1}$ was unambiguously determined as quercetin 3-O- $\beta$-D-galactopyranosyl- $(1 \rightarrow 2)-\alpha$-L-rhamnopyranoside$(1 \rightarrow 6)-\alpha$-L-rhamnopyranoside (Figure 1$){ }^{35}$

The molecular formula for compound $\mathbf{2}$ was established as $\mathrm{C}_{32} \mathrm{H}_{38} \mathrm{O}_{20}$ based on HRMS data $[\mathrm{M}-\mathrm{H}]^{-}$at 741.1936 , 14 units less mass than had the compound $\mathbf{1}$. Furthermore, the ${ }^{1} \mathrm{H}$ and ${ }^{13} \mathrm{C}$ NMR spectroscopic data for compound $\mathbf{2}$ were similar to those of compound $\mathbf{1}$, except for the data 
attributed to apiose unit: $\delta_{\mathrm{H}} 5.45(\mathrm{~d}, J 1.4 \mathrm{~Hz}, \mathrm{H}-1$ "'), 4.05 (sl, H-2"'), doublets at 4.04 and $3.69(J 9.5 \mathrm{~Hz}$, H-4"') and doublets at 3.73 and 3.63 ( $J 11.5 \mathrm{~Hz}, \mathrm{H}-5$ ", $)$, which were correlated to carbons at $\delta_{\mathrm{C}} 110.7$ (C-1"”), 78.1 (C-2"'), 75.5 (C-4"') and 66.2 (C-5"'), respectively, using HSQC spectra. The observation of one non-hydrogen bonded carbon at $\delta_{\mathrm{C}} 80.8$ (C-3") was compatible with the presence of this sugar unit. Three doublets integrating to one hydrogen each at $\delta_{\mathrm{H}} 5.45(J 1.4 \mathrm{~Hz})$, $5.41(\mathrm{~J} 7.8 \mathrm{~Hz})$ and $4.51(\mathrm{~J} 1.5 \mathrm{~Hz})$ indicated the presence of three anomeric protons, which correlated to carbons at $\delta_{\mathrm{C}} 110.7$ (C-1"'Api), 101.5 (C-1"'Gal) and 101.8 (C-1"'"Rha), respectively, in the $\mathrm{HSQC}$ spectra. The linkage among the three sugar units was established from the HMBC correlation between the signals of the anomeric protons of the apiose at $\delta_{\mathrm{H}} 5.45$ and of the rhamnose at $\delta_{\mathrm{H}} 4.51$ with the carbon signals of the galactose at $\delta_{\mathrm{C}} 76.7$ (C-2") and 67.0 (C-6"), respectively (1D and 2D NMR spectra are shown in SI section, Figures S4-S8). Thus, compound 2 was determined as quercetin 3-O- $\beta$-D-galactopyranosyl$(1 \rightarrow 2)$ - $\alpha$-apiopyranoside-( $1 \rightarrow 6)$ - $\alpha$-L-rhamnopyranoside (Figure 1).

The NMR spectra data of compounds $\mathbf{3}$ and $\mathbf{4}$ were similar to those of compounds $\mathbf{1}$ and $\mathbf{2}$, showing that the aglycone moiety is the same among them. However, compound $\mathbf{3}$ showed typical signals of a single sugar residue at the C-3 (glucose, doublet at $\delta_{\mathrm{H}} 5.15, J 7.8 \mathrm{~Hz}$ ), while compound 4 has a methoxyl group (singlet at $\delta_{\mathrm{H}} 3.77$ ) at this position, which were confirmed from the HMBC correlations.

Thus, these two known flavonoids were identified by direct comparison of their spectra data with those previously reported for quercetin 3-O-glucopyranoside $(3)^{23,36,37}$ and 3-O-methyl-quercetin (4) $)^{38-40}$ (Figure 1). The molecular formulas were established as $\mathrm{C}_{21} \mathrm{H}_{20} \mathrm{O}_{12}$ for compound $\mathbf{3}$ and $\mathrm{C}_{16} \mathrm{H}_{11} \mathrm{O}_{7}$ for compound 4 based on HRMS data $[\mathrm{M}-\mathrm{H}]^{-}$at 463.0836 and at 315.0487 , consistent with the proposed structures. The detailed information of NMR data is shown in SI section (Tables $\mathrm{S} 1$ and $\mathrm{S} 2$ ).

To the best of our knowledge, this study represents the first report of the isolation of compound $\mathbf{2}$ as a natural product. The others are already reported in the literature, compound 1 has been isolated from Bougainvillea glabra: ${ }^{35}$ compound 3 from Croton pedicellatus ${ }^{23}$ and compound 4 from Croton echioides, Croton schiedeanus and Croton zehntineri. ${ }^{41-43}$

\section{Conclusions}

A method to obtain the fingerprint chromatograms of three extracts of leaves from four accessions of
C. grewioides Baill., collected in summer and winter, was developed by using HPLC-DAD. The influence of the seasonality and the extraction method on the chemical profile of this species could be evaluated after analyzing the chromatographic data using chemometric tools. The compounds present in the methanol extracts of accessions 101 and 113 were quantitatively different between the two seasons, showing the seasonality effect. On the other hand, in relation to the extraction method, the chemical profiles of the hydroalcoholic extracts and decoction of all the accessions were similar, which differed from their respective methanolic extracts. It is also suggested that the accession 101 is a specific genetic variety based on its chemical profile and confirmed through its projection in the scores plot.

A semi-preparative method was developed allowing the isolation and subsequent characterization of four flavonoid derivatives including a new triglycosylated derivative, identified as quercetin 3-O- $\beta$-D-galactopyranosyl$(1 \rightarrow 2)$ - $\alpha$-apiopyranoside- $(1 \rightarrow 6)$ - $\alpha$-L-rhamnopyranoside.

Finally, based on the scores and loadings graphs it is possible to acknowledge that the compounds $\mathbf{1 ,} 2$ and $\mathbf{3}$ differentiate hydroalcoholic and decoction extracts from methanolic extracts, while compound $\mathbf{3}$ is the only one that characterizes the hydroalcoholic and decoction extracts (winter and summer) from accession 101, because of all the identified compounds in the chromatogram compound $\mathbf{3}$ presented negative values for PC1 and positive values for PC2 in the loadings plot.

Knowing the numerous pharmacological activities presented by flavonoids, our results support future research where there is an interest in the medicinal use of this plant, suggesting that the season of collection and the method of extraction of the chemical constituents from this species should be taken into account.

\section{Supplementary Information}

Supplementary data is available free of charge at http://jbcs.sbq.org.br as PDF file.

\section{Acknowledgments}

This research work was financially supported by the CNPq, CAPES, and FAPESP (PROEM 2014/50299-5, research grant 2013/01710-1 and by the PD-grant 2014/11640-3). The authors thank the Brazilian funding agencies CNPq and CAPES for their financial support. A.F.B., E.R.P.F., Q.B.C., A.G.F. and P.C.L.N. are grateful to $\mathrm{CNPq}$ for research fellowships. 


\section{Author Contributions}

Vilma M. J. Prado was responsible for formal analysis, investigation, methodology, project administration and writing-original draft; Raphael A. de Jesus for the formal analysis, methodology, project administration, supervision and writing-original draft; Julio M. A. Oliveira for the formal analysis, investigation and methodology; Camila S. A. Pereira for the conceptualization, investigation and methodology; Arie F. Blank for the conceptualization, investigation, methodology and supervision; Edenir R. Pereira-Filho for the formal analysis, methodology, software and validation; Quezia B. Cass for the formal analysis, investigation, methodology and writing-review and editing; Juliana M. de Lima for the formal analysis, investigation and methodology; Antonio G. Ferreira for the formal analysis, investigation and methodology; Paulo C. L. Nogueira for the conceptualization, funding acquisition, methodology and project administration; Valéria R. S. Moraes for the project administration, supervision, visualization and writing- original draft.

\section{References}

1. Secco, R. S.; Cordeiro, I.; Senna-Vale, L.; Sales, M. F.; Lima, L. R.; Medeiros, D.; Haiad, B. S.; Oliveira, A. S.; Caruzo, M. B. R.; Carneiro-Torres, D.; Bigio, N. C.; Rodriguesia 2012, 63, 227.

2. Lucena, M. F. A.; Sales, M. F.; Rodriguesia 2006, 57, 11.

3. Figueiredo, W. R. S.; Oliveira, F. Q.; Oliveira, R.; Batista, J. L.; Brito, C. H.; Eng Amb. Espírito Santo do Pinhal 2010, 7, 113, available at http://ferramentas.unipinhal.edu.br/ engenhariaambiental/viewarticle.php?id=566 accessed in September 2020.

4. Silva, J. S.; Sales, M. F.; Gomes, A. P. S.; Carneiro-Torres, D. S.; Acta Bot. Bras. 2010, 24, 441.

5. Silva, C. G.; Marinho, M. G. V.; Lucena, M. F. A.; Costa, J. G. M.; Rev. Bras. Pl. Med. 2015, 17, 133.

6. Ravanelli, N.; Santos, K. P.; Motta, L. B.; Lago, J. H. G.; Furlan, C. M.; S. Afr. J. Bot. 2016, 102, 153.

7. Silva, C. G. V.; Zago, H. B.; Júnior, H. J. G. S.; Camara, C. A. G.; Oliveira, J. V.; Barros, R.; Schwartz, M. O. E.; Lucena, M. F. A.; J. Essent. Oil Res. 2008, 20, 178.

8. Medeiros, V. M.; Nascimento, Y. M.; Souto, A. L.; Madeiro, S. A. L.; Costa, V. C. O.; Silva, S. M. P. M.; Silva, V. S. F.; Agra, M. F.; Siqueira-Júnior, J.P.; Tavares, J. F.; Microb. Pathog. 2017, 111, 468.

9. Silva, A. D. S.; Melo e Silva, K.; Neto, J. C.; Costa, V. C. O.; Pessôa, H. L. F.; Tavares, J. F.; Silva, M. S.; Cavalcante, F. A.; Pharmacogn. Res. 2016, 8, 202.

10. Castro, K. N. C.; Chagas, A. C. S.; Costa-Júnior, L. M.; Canuto, K. M.; Brito, E. S.; Rodrigues, T. H. S.; Andrade, I. M.; Rev. Bras. Farmacogn. 2019, 29, 811.
11. Medeiros, V. M.: Estudo Fitoquímico de Croton grewioides Baill. e Revisão da Ocorrência das Principais Classes de Metabólitos do Gênero Croton; PhD thesis, Universidade Federal da Paraíba, João Pessoa, Brazil, 2012, available at https://repositorio.ufpb.br/jspui/handle/tede/6782?locale=pt_ BR, accessed in September 2020.

12. Gobbo-Neto, L.; Lopes, N. P.; Quim. Nova 2007, 30, 374.

13. Gupta, A.; Naraniwal, M.; Kothari, V.; Int. J. Appl. Nat. Sci. 2012, 1,8 .

14. Gololo, S. S.; Shai, L. J.; Agyei, N. M.; Mogale, M. A.; J. Pharmacogn. Phytother. 2016, 8, 168.

15. Skrzypczak-Pietraszek, E.; Pietraszek, J.; J. Pharm. Biomed. Anal. 2012, 66, 154.

16. Martins, L. R. R.; Pereira-Filho, E. R.; Cass, Q. B.; Anal. Bioanal. Chem. 2011, 400, 469.

17. Giri, L.; Andola, H. C.; Purohit, V. K.; Rawat, M. S. M.; Rawal, R. S.; Bhatt, I. D.; Res. J. Phytochem. 2010, 4, 234.

18. Pirouette, v.4.0; Infometrix, Woodinville, WA, USA, 2014.

19. Skov, T.; van den Berg, F.; Tomasi, G.; Bro, R.; J. Chemom. 2006, 20, 484.

20. Gomes, S. V. F.; Santos, A. D. C.; Moraes, V. R. S.; Martins, L. R. R.; Viana, M. D.; Blank, A. F.; Pereira-Filho, E. R.; Cass, Q. B.; Nogueira, P. C. L.; Alves, P. B.; Chromatographia 2010, 72, 275.

21. Santos, C. P.; Pinheiro, J. B.; Zucchi, M. I.; Bajay, M. M.; Campos, J. B.; Arrigoni-Blank, M. F.; Pinto, J. A. O.; Blank, A. F.; Genet. Mol. Res. 2016, 15, DOI: 10.4238/gmr.15037781.

22. Pinto, J. E. S. S. In Atlas Escolar Sergipe: Espaço Geo-Histórico e Cultural; França, V. L. A.; e Cruz, M. T. S., eds.; Grafset: João Pessoa, 2007, p. 200.

23. Lopes, E. L.; Neto, M. A.; Silveira, E. R.; Pessoa, O. D. L.; Braz-Filho, R.; Quim. Nova 2012, 35, 2169.

24. Rossi, D.; Guerrini, A.; Maietti, S.; Bruni, R.; Paganetto, G.; Poli, F.; Scalvenzi, L.; Radice, M.; Saro, K.; Sacchetti, G.; Food Chem. 2011, 126, 837.

25. Maciel, M. A. M.; Pinto, A. C.; Brabo, S. N.; Silva, M. N.; Phytochemistry 1998, 49, 823.

26. Yang, L.; Zhang, Y.-B.; Chen, L.-F.; Chen, N.-H.; Wu, Z.-N.; Jiang, S.-Q.; Jiang, L.; Li, G.-Q.; Li, Y.-L.; Wang, G.-C.; Bioorg. Med. Chem. Lett. 2016, 26, 4687.

27. Tian, J.-L.; Yao, G.-D.; Wang, Y.-X.; Gao, P.-Y.; Wang, D.; Li, L.-Z.; Lin, B.; Huang, X.-X.; Song, S.-J.; Bioorg. Med. Chem. Lett. 2017, 27, 1237.

28. Kong, W. J.; Zhao, Y. L.; Xiao, X. H.; Jin, C.; Li, Z. L.; Phytomedicine 2009, 16, 950.

29. Viapiana, A.; Struck-Lewicka, W.; Konieczynski, P.; Wesolowski, M.; Kaliszan, R.; Front. Plant Sci. 2016, 7, DOI: 10.3389/fpls.2016.01561.

30. Lu, Y.; Gao, B.; Chen, P.; Charles, D.; Yu, L. (L).; Food Chem. 2014, 154, 262.

31. Sun, Z.; Zhao, L.; Cheng, N.; Xue, X.; Wu, L.; Zheng, J.; Cao, W.; J. Pharm. Anal. 2017, 7, 317. 
32. Pardo-Mates, N.; Vera, A.; Barbosa, S.; Hidalgo-Serrano, M.; Núñez, O.; Saurina, J.; Hernández-Cassou, S.; Puignou, L.; Food Chem. 2016, 221, 29.

33. Zhang, L.; Liu, Y.; Wang, Y.; Xu, M.; Hu, X.; Food Chem. 2018, 263, 208.

34. Mabry, T. J.; Markham, K. R.; Thomas, M. B.; The Systematic Identification of Flavonoids; Springer-Verlag, BerlinHeidelberg: New York, USA, 1970, p. 354.

35. Simon, A.; Tóth, G.; Duddeck, H.; Soliman, H. S. M.; Mahmoud, I. I.; Samir, H.; Nat. Prod. Res. 2006, 20, 63.

36. Islam, M.; Al-Amin, M.; Siddiqi, M. M. A.; Akter, S.; Haque, M. M.; Sultana, N.; Chowdhury, A. S.; Dhaka Univ. J. Sci. 2012, 60, 11.

37. Pereira, C.; Barreto-Júnior, C. B.; Kuster, R. M.; Simas, N. K.; Sakuragui, C. M.; Porzel, A.; Wessjohann, L.; Quim. Nova 2012, 35, 1123.
38. Wang, J.; Gao, H.; Zhao, J.; Wang, Q.; Zhou, L.; Han, J.; Yu, Z.; Yang, F.; Molecules 2010, 15, 5998.

39. Lee, E. H.; Kim, H. J.; Song, Y. S.; Jin, C.; Lee, K.-T.; Cho, J.; Lee, Y. S.; Arch. Pharm. Res. 2003, 26, 1018.

40. Jung, M.; Park, M.; Molecules 2007, 12, 2130.

41. Correa-Hernández, S. X.; Puebla-Ibánez, P.; de la Calle, R. C.; Martín-Calvo, M. L.; del Barrio, L. S. R.; Pabón, M. F. G.; Rev. Fac. Med. 2008, 56, 291.

42. Santos, H. S.; Furtado, E.; Rodrigues, A. S.; Bandeira, P. N.; Lemos, T. L. G.; Bezerra, A. M. C.; Braz-Filho, R.; J. Pharmacogn. Phytochem. 2017, 6, 1146.

43. Novello, C. R.; Marques, L. C.; Pires, M. E.; Kutschenco, A. P.; Nakamura, C. V.; Nocchi, S.; Sarragiotto, M. H.; Mello, J. C. P.; J. Braz. Chem. Soc. 2016, 27, 2203.

Submitted: March 22, 2020 Published online: September 18, 2020 